\title{
Determination of isotopic composition and concentration of uranium and boron by thermal ionization mass spectrometric isotopic dilution technique
}

\author{
Hilal Shahab Wahab ${ }^{1, *}$, Khalil Ibraheem Hussain ${ }^{2}$ \\ ${ }^{1}$ Department of chemistry, College of Science, Al-Nahrain University, Al-Jadriya, Baghdad, Iraq \\ ${ }^{2}$ Department of chemistry, College of Education - Ibn Al-Haitham, University of Baghdad, Al-Aadhamiya, Baghdad, Iraq
}

\section{Email address:}

hswahab@yahoo.com (H. S. Wahab)

\section{To cite this article:}

Hilal Shahab Wahab, Khalil Ibraheem Hussain. Determination of Isotopic Composition and Concentration of Uranium and Boron by Thermal Ionization Mass Spectrometric Isotopic Dilution Technique. American Journal of Applied Chemistry. Vol. 2, No. 2, 2014, pp. 27-32. doi: 10.11648/j.ajac.20140202.11

\begin{abstract}
In this study, the determination of isotopic composition and concentration of uranium and boron by mass spectrometric isotopic dilution have been performed .The isotopic composition was measured using thermal ionization mass spectrometer methodology employing U-233 and B-10 as spike isotope standards. The accuracy and reproducibility of the isotopic ratio and concentration measurements were evaluated.
\end{abstract}

Keywords: Mass Spectrometry, Boron Isotopes, Uranium Isotopes, Isotope Dilution Technique

\section{Introduction}

Boron and uranium are extremely important elements in the field of nuclear science researches, due to the nuclear fuel backbone of uranium and the ${ }^{10} \mathrm{~B}(\mathrm{n}, \alpha){ }^{7} \mathrm{Li}$ neutron capture reaction [1]. Furthermore, boron is used in a primary coolant system in pressurized water reactors in the form of boric acid to control the reactivity in the core [2]. Accordingly, the precise quantification of their isotopic composition is of great interest in nuclear industry and also in environmental studies [3] .Isotope dilution technique (IDT) has been extensively employed by several authors for the determination of boron [4-7] and uranium [8-10].

The key stipulation of IDT analysis is existence of at least two stable isotopes for the element under consideration, because the method is based on the ratios of the isotopes [11-12] .This limitation, however, is somewhat less restrictive because a number of elements have artificial isotopes of long half-life which undergo negligible decay over the duration of the determination. The stable isotope dilution method can be used for the analysis of about $80 \%$ of the elements. The sensitivity of the method varies from element to another, from a few $\boldsymbol{\mu} \mathrm{g}$ to $10^{-3} \mathrm{gm}$ or even less.

In step with development of mass spectrometry, Isotopic dilution technique has found widespread application in solving complicated analytical problems, in the determination of geological age, in establishing yields of fission products and conditions of radioactive splitting and in studying a number of other nuclides as burn up monitors [13-15] for the burn up determination of the isotopic composition of fissile elements in the initial and irradiated fuel or the measurement of some stable fission products which serve as burn up monitors.

\section{Experimental}

\subsection{Apparatus}

Thermal ionization mass spectrometer (MAT 261), Finnegan Mat Co. (Germany)

The conditions for boron isotope analysis were as follows:

The applied current on evaporation and ionization filaments was $1.5-1.7 \mathrm{~A}$

Temperature range $750-1000{ }^{\circ} \mathrm{C}$

Ion measured $\mathrm{Na}_{2} \mathrm{BO}_{2}^{+}$

Mass: 88 correspond to $\mathrm{Na}_{2} \mathrm{~B}^{10} \mathrm{O}_{2}^{+}$

: 89 correspond to $\mathrm{Na}_{2} \mathrm{~B}^{11} \mathrm{O}_{2}^{+}$

The currents of evaporation and ionization filaments were step wise increased ( $0.2 \mathrm{~A}$ every $3 \mathrm{~min}$.) so a stable and intense isotope peak of $\mathrm{B}^{10}$ and $\mathrm{B}^{11}$ is reached in a period of twenty minutes [16].

The experimental parameters for uranium isotopes determination were as follows: 
Applied current: evaporation filament $2 \mathrm{~A}$

Ionization filament $5.6 \mathrm{~A}$

Ion measured: $\mathrm{U}^{+}$

Masses: 233, 234, 235 and 238

Pilot isotope: 238

\subsection{Boron Measurement Reagents}

National Bureau of Standards (NBS) reference material of boron was employed for this type of analysis and it includes the following:

NBS 951 boric acid with the following certificate of analysis: $\mathrm{H}_{3} \mathrm{BO}_{3}$, acidimetric assay, wt. \% $100.00 \pm 0.10$

Absolute abundance ratio, $\mathrm{B}^{10} / \mathrm{B}^{11} 0.2473 \pm 0.0002$

Boron 10, Atom\% $19.827 \pm 0.013$

Boron 11, Atom\% 80.173 \pm 0.013

NBS 952 (Enriched boric acid) used as spike with the following specifications:
Absolute abundance ratio $\mathrm{B}^{10} / \mathrm{B}^{11} \quad 18.80 \pm 0.02$
Boron 10, Atom\% $94.949 \pm 0.005$
Boron 11, Atom\% $5.051 \pm 0.005$
$\mathrm{H}_{3} \mathrm{BO}_{3}$, acidimetric assay, wt. \% $99.97 \pm 0.02$

\subsection{Boron Measurement Procedure}

Boric acid solution (3400 ppm boron) was prepared by dissolving $0.1034 \mathrm{gm}$ of certified NBS 951 boron standard in distilled water and then was titrated with $0.05 \mathrm{M} \mathrm{NaOH}$ to reach a $\mathrm{pH}$ range of 8-8.5 using Hanna HI2209 $\mathrm{pH}$ meter. This range of acidity value is very essential to ensure complete conversion of boric acid to sodium tetraborate according to the following stoichiometric equation:

$$
4 \mathrm{H}_{3} \mathrm{BO}_{3}+2 \mathrm{NaOH} \rightarrow \mathrm{Na}_{2} \mathrm{~B}_{4} \mathrm{O}_{7} .7 \mathrm{H}_{2} \mathrm{O}
$$

The formation of sodium borate is necessary [17-18] and was performed completely since in thermal ionization mass spectrometer, the conversion of $\mathrm{Na}_{2} \mathrm{~B}_{4} \mathrm{O}_{7}$ gives almost exclusively $\mathrm{Na}_{2} \mathrm{BO}_{2}{ }^{+}$ions having the masses $88\left(\mathrm{~B}^{10}\right)$ and $89\left(\mathrm{~B}^{11}\right)$. Similarly another solution of NBS boron isotope standard No.952 (spike) was prepared (3151 ppm) for the purpose of isotopic ratio measurements of samples of unknown isotopic abundance and also to measure the concentration using the isotopic dilution technique. An aliquot of $14 \mu \mathrm{g}$ of the above mentioned boron standard was loaded on the rhenium filament of the mass spectrometer, and the isotopic ratio measurements of boron $\left(\mathrm{B}^{10} / \mathrm{B}^{11}\right)$ were conducted.

\subsection{Uranium Measurement Reagents}

Uranium secondary standards of different enrichments $\left(0.32,0.72,10 \% \mathrm{U}^{238}\right)$

Spike standard of $\mathrm{U}^{233}$, mass analysis expressed as atom percent:

$\begin{array}{ll}\mathrm{U}^{233} & 99.7035 \pm 0.0005 \\ \mathrm{U}^{234} & 0.2355 \pm 0.0001 \\ \mathrm{U}^{235} & 0.0125 \pm 0.0001 \\ \mathrm{U}^{236} & 0.00 \\ \mathrm{U}^{238} & 0.00485 \pm 0.0002\end{array}$

\subsection{Uranium Measurement Procedure}

A series of different concentrations of uranium solutions (natural isotopic abundance) were prepared using uranyl nitrate hexahydrate dissolved in $1 \mathrm{M} \mathrm{HNO}_{3}$, After complete loading of uranium samples on the rhenium thermal ionization filaments (melting point $\sim 3180 \mathrm{C}^{\circ}$ ), the magazine, holding 13 filaments, was then inserted in the ion source chamber and the analyzer head was evacuated to a workable pressure of $\sim 10^{-7}$ mbar.

\section{Results}

\subsection{Boron Measurements}

Precision and accuracy of boron measurements were calculated and compared with the certified value as shown in Table 1. To evaluate the net peak heights of the masses 88 and 89 , a correction was made for oxygen-17 portions in the mass 89 which corresponds to the $\mathrm{B}^{11}$ isotope in the ion $\mathrm{Na}_{2} \mathrm{~B}^{11} \mathrm{O}_{2}^{+}$. [19]:

The formula applied for such correction is listed below

$$
\left(\mathrm{B}^{10} / \mathrm{B}^{11}\right)_{\text {corrected valua }}=\frac{\left(\mathrm{B}^{10} / \mathrm{B}^{11}\right)_{\text {measured }}}{1-\left(\mathrm{B}^{10} / \mathrm{B}^{11}\right)_{\text {measured }} \mathrm{X} 0.00079}
$$

However for the application of isotopic dilution technique, a series of boron mixtures were prepared by mixing a known aliquot of spike solution (3151 ppm boron) with certain portion of freshly prepared standard solution (3400 ppm boron) exploiting N.B.S boron standard No.951. The mixture was chosen to represent a series of different ratios of the standard to the spike as shown in Table 2. For the calculation of boron concentration in the standard (taken as unknown), the following equation is usually used for isotopic dilution analysis [20].

$$
C x=C s \cdot \frac{m s}{m p} \cdot \frac{M p}{M s} \cdot \frac{H_{10}^{s}}{H_{11}^{p}} \cdot \frac{\left.\left[\left(1 / V_{10}\right)_{m i x}-\left(1 / V_{10}\right)_{s}\right)\right]}{\left[1-\left(V_{10}\right)_{p} /\left(V_{10}\right)_{m i x}\right]}
$$

Where

$\mathrm{Cx}=$ Boron concentration in the standard (unknown) in ( $\frac{\text { mg boron }}{\text { gm. sol. }}$ )

$\mathrm{Cs}=$ Boron concentration in the spike (NBS-952) in ( $\frac{\text { mg boron }}{\mathrm{am}}$ )

$\mathrm{ms}=$ Amount of spike solution (weight) in $\mathrm{mg}$ $\mathrm{mp}=$ Amount of standard solution (weight) in $\mathrm{mg}$

$\mathrm{Mp}=$ mean atomic weight of boron in the unknown solution

$\mathrm{Ms}=$ mean atomic weight of boron in the spike solution

$\mathrm{H}^{\mathrm{S}}{ }_{10}=$ Atomic $\% \mathrm{~B}^{10}$ in the standard (unknown)

$\mathrm{H}^{\mathrm{P}}{ }_{11}=$ Atomic $\% \mathrm{~B}^{11}$ in the spike

$\left(\mathrm{v}_{10}\right)_{\mathrm{P}}=$ Atomic ratio of $\mathrm{B}^{10} / \mathrm{B}^{11}$ in the unknown

$\left(\mathrm{v}_{10}\right)_{\mathrm{S}}=$ Atomic ratio of $\mathrm{B}^{10} / \mathrm{B}^{11}$ in the spike 
$\left(\mathrm{v}_{10}\right)_{\text {mix }}=$ Atomic ratio of $\mathrm{B}^{10} / \mathrm{B}^{11}$ in the mixture

The isotopic ratio measurements of six mixtures were determined by the mass spectrometer and the boron isotope ratios $\left(\mathrm{B}^{10} / \mathrm{B}^{11}\right)$ were also corrected for the presence of oxygen-17. The concentration of boron samples determined by isotopic dilution method is compared with the given values as shown in Table 3 .

\subsection{Uranium Measurements}

Isotopic composition measurements for each concentration of uranium were performed and the isotopic ratios, abundance and atom $\%$ were then calculated along with the standard deviation as shown in Tables 4 and 5. For further scrutinization the impact of uranium concentration on the precision and accuracy of isotopic ratio determination has been studied employing a series of different uranium concentrations of similar enrichment value as the results are presented in Table 6. Furthermore, different uranium enrichment solutions were prepared with the same uranium concentration (2000 ppm U) and then an amount of $10 \mu \mathrm{g}$ of each sample was loaded onto the rhenium evaporation filament. The isotopic ratio determinations are shown in Table 6.

For isotopic dilution analysis of uranium, two mixtures were prepared by mixing U-233 spike standard (1000 ppm $\mathrm{U})$ with a natural abundance uranium secondary standard (2422 ppm U). The mixture then evaporated to dryness and redissolved in $1 \mathrm{M}$ nitric acid to ensure a complete isotopic exchange. The amount taken and the measured ratios of $\left(\mathrm{U}^{233} / \mathrm{U}^{238}\right)$ of these two mixtures are shown in Table 7. Other isotopic ratios were also calculated including $\mathrm{U}^{234} / \mathrm{U}^{238}, \quad \mathrm{U} 235 / \mathrm{U}^{238}, \quad \mathrm{U} 236 / \mathrm{U}^{238}$ and $\mathrm{U}^{235} / \mathrm{U}^{233}$. Furthermore $238 / 238$ has been calculated according to the following expression [21]:

$$
238 / 238=\left[\left(\frac{234}{235}\right)\left(\frac{235}{238}\right)\right] /(234 / 238)
$$

The concentration of the spike solution taken as unknown were calculated using the following formula:

$$
\left[U^{233}\right]=\frac{R m-R i}{1-\left(\frac{R m}{R p}\right)} \cdot \frac{W i^{238}}{W p^{233}} \cdot\left[U^{238}\right]
$$

Where

$R=\frac{U^{233}}{U^{238}}$

$\mathrm{Rm}=\mathrm{R}$ in mixture

$\mathrm{Ri}=\mathrm{R}$ in spike (taken as unknown)

$R i=\frac{U^{233}}{U^{238}}$ in spike $\left(\mathrm{U}^{238}\right.$ in this work)

$R p=\frac{U^{233}}{U^{238}}$ in the unknown (spike $\left.\mathrm{U}^{233}\right)$

$\mathrm{w}=$ weight $(\mathrm{wt})$

$$
\begin{aligned}
& \mathrm{i}=\operatorname{spike}\left(\mathrm{U}^{238}\right), \mathrm{g} \\
& \mathrm{P}=\text { unknown }\left(\mathrm{U}^{233}\right), \mathrm{g}
\end{aligned}
$$

\section{Discussion}

For isotopic analysis of boron which is performed with thermionic mass spectrometer, precise value maintenance of filament current is essential to produce a stable intense peak and to avoid or minimize the isotopic fractionation usually appears in the analysis of light element using a thermal ionization mass spectrometer [22]. The results of analysis of two N.B.S boron standards as shown in Table 1, represents the reproducibility and accuracy of boron isotope measurements. The reproducibility of isotopic composition determination depends on the abundance of the individual isotopes. The error in the isotopic ratio measurements obtained for boron standards is higher by a factor of 0.1 for (N.B.S-951) and 0.64 for (N.B.S-952). The measurements of boron concentration by isotopic dilution analysis as represented in Table 3 , reveals an average value of $3185 \mathrm{ppm}$ of the determined boron in comparison to the given value of $3151 \mathrm{ppm}$. Variation in the isotopic ratio of standard to spike sample results in obtaining different ratios of $\mathrm{B}^{10} / \mathrm{B}^{11}$ isotopes. The variation in the isotopic ratios in these mixtures of boron samples showed a little effect on the measurement of boron concentration. The error of boron concentration measurements $(1.08 \%)$ is acceptable and in a good agreement with that published in the literature $[18,22]$.

Tables 4 and 6 represent the measurements of isotopic ratio composition of uranium samples with a scan of various concentration and different enrichment values to verify the feasibility of the mass spectrometer, the precision and the accuracy of the analysis. It is known that the isotope ratio measured in thermal ionization mass spectrometry is not the same as the actual isotope ratio of sample on the filament. The measured ratio varies during the analysis due to isotope fractionation occurring in the ionic emission process and this fractionation limits the accuracy of most of the isotopic analysis [12]. Reasonable isotopic ratio measurements were accomplished for depleted natural and enriched uranium samples. Data for the measurements of uranium concentration by isotopic dilution technique is given in Table 7 which shows the mixing ratio of $\mathrm{U}^{238}$ and $\mathrm{U}^{233}$ for the isotopic dilution analysis of $\mathrm{U}^{233}$. It is seen also from Table 7 , that the ratio 3:1 gives better results in comparison with ratio $12: 1$. This could be attributed to the large difference in the peak height of these isotopes. Consequently one can conclude that lower ratio could give more reliable results because of the similar peak intensity of the mixed isotopes. Based on the above results, one could conclude that precision of an isotopic abundance measurement varies with the number of average observations and with the abundance level of the isotope in question. Total error in concentration measurements of uranium samples by isotopic dilution analysis consists of the following errors: 
A. Absence of N.B.S uranium primary standards.

B. Different errors of mass-spectrometric measurement; error caused by contamination of the sample and the filament, error of mass spectrometer calibration, statistical error of the measurement and error due to the interfering isotopes.

C. The errors emerged from weighing of sample and spike.

D. Errors caused by incomplete isotope exchange between spike and sample.

Table 1. Test of the reproducibility and accuracy of boron isotope analysis.

\begin{tabular}{llll}
\hline \multirow{2}{*}{ sample } & \multirow{2}{*}{ No. of measurements } & \multicolumn{2}{c}{${\mathbf{R}\left(\mathbf{B}^{\mathbf{1 0}} / \mathbf{B}^{\mathbf{1 1}}\right)}$} \\
\cline { 2 - 4 } & & Certified & Measured \\
\hline NBS 951 & 15 & $0.2473 \pm 0.0002$ & $0.2475 \pm 0.00006(\sigma \mathrm{n})$ \\
NBS 952 & 15 & $18.8000 \pm 0.0130$ & $18.6366 \pm 0.00563(\sigma \mathrm{n})$ \\
\hline
\end{tabular}

Table 2. Mixtures of boron representing a series of different ratios of standard to the spike sample*.

\begin{tabular}{llll}
\hline No. & Amount of (NBS-951), $\mathbf{g}$ & Amount of (NBS-952), $\mathbf{g}$ & Ratio of (951) / (952) \\
\hline 1 & 0.0997 & 0.0498 & $1: 0.5$ \\
2 & 0.0997 & 0.1000 & $1: 1$ \\
3 & 0.0991 & 0.1987 & $1: 2$ \\
4 & 0.0993 & 0.4936 & $1: 5$ \\
5 & 0.0988 & 0.9980 & $1: 10$ \\
6 & 0.0497 & 1.0008 & $1: 20$ \\
\hline
\end{tabular}

* Densities of NBS-951 $=1.005 \mathrm{~g} / \mathrm{m} 1$ and of NBS-952 $=1.0008 \mathrm{~g} / \mathrm{m} 1$

Table 3. Boron concentration measurements by isotope dilution analysis.

\begin{tabular}{|c|c|c|c|c|c|}
\hline $\begin{array}{l}\text { Mixture } \\
\text { No. }\end{array}$ & $\begin{array}{l}\text { No. of } \\
\text { runs }\end{array}$ & $R\left(\frac{N B S 951 \text { std } .}{\text { NBS } 952 \text { spike }}\right)$ & $\begin{array}{l}\mathbf{R}\left(\mathrm{B}^{10} / \mathrm{B}^{11}\right)_{\operatorname{mix}} \\
\text { After correction For } \mathrm{O}^{17}\end{array}$ & $\begin{array}{l}\text { Boron conc. } \\
\text { (ppm) taken }\end{array}$ & $\begin{array}{l}\text { Boron conc. }(\mathrm{ppm}) \\
\text { found }\end{array}$ \\
\hline 1 & 4 & $1: 0.5$ & $0.81292 \pm 0.0002$ & 3151 & 3174 \\
\hline 2 & 5 & $1: 1$ & $1.3532 \pm 0.0018$ & 3151 & 3187.5 \\
\hline 3 & 4 & $1: 2$ & $2.3323 \pm 0.002$ & 3151 & 3193.2 \\
\hline 4 & 4 & $1: 5$ & $4.6481 \pm 0.0171$ & 3151 & 3178.5 \\
\hline 5 & 6 & $1: 10$ & $7.4055 \pm 0.0017$ & 3151 & 3182.5 \\
\hline \multirow[t]{2}{*}{6} & 4 & $1: 20$ & $10.5164 \pm 0.0708$ & 3151 & 3195 \\
\hline & & & & Mean $x=3185$ & \\
\hline
\end{tabular}

Table 4. Determination of isotopic ratio of uranium at different concentrations using natural uranium standard (0.72\% enrichment).

\begin{tabular}{|c|c|c|c|c|}
\hline \multicolumn{5}{|c|}{ Sample No. 1. Conc. : 4000 ppm; No. of runs $=5$, Vol.: $5 \mu 1=20 \mu \mathrm{g} /$ filament } \\
\hline Isotope & $\mathrm{U}^{238}$ & $\mathrm{U}^{236}$ & $\mathrm{U}^{235}$ & $\mathrm{U}^{234}$ \\
\hline Mean ratio & 0.997532 & 0.000001 & 0.007314 & 0.000054 \\
\hline Std. deviation & 0.0034977 & 0.000002 & 0.00000102 & 0.0000009 \\
\hline Atomic $\%$ & 99.2667 & 0.0001 & 0.7278 & 0.0054 \\
\hline Mean wt. & 236.2548 & 0.000236 & 1.710330 & 0.012636 \\
\hline wt.\% & 99.2759 & 0.001 & 0.7287 & 0.0053 \\
\hline \multicolumn{5}{|l|}{ Mean atomic wt. } \\
\hline \multicolumn{5}{|c|}{ Sample No. 2. Conc.: 3000 ppm; No. of Runs = 5, Vol.: $5 \mu 1=15 \mu \mathrm{g}$ / filament } \\
\hline Isotope & $\mathrm{U}^{238}$ & $\mathrm{U}^{236}$ & $\mathrm{U}^{235}$ & $\mathrm{U}^{234}$ \\
\hline Mean ratio & 1.000783 & 0.000000 & 0.07316 & 0.00061 \\
\hline Std. deviation & 0.0049412 & 0.0000007 & 0.0000849 & 0.00000192 \\
\hline Atomic\% & 99.2683 & 0.000000 & 0.7257 & 0.006 \\
\hline Mean wt. & 236.2585 & 0.0000 & 1.7054 & 0.0140 \\
\hline wt.\% & 99.2774 & 0.0000 & 0.7166 & 0.0059 \\
\hline \multirow[t]{2}{*}{ Mean atomic wt. } & 237.9780 & & & \\
\hline & \multicolumn{4}{|c|}{ Sample No. 3 Conc. : 2000 ppm; No. of Runs = 5, Vol.: $5 \mu 1=20 \mu \mathrm{g}$ / filament } \\
\hline Isotope & $\mathrm{U}^{238}$ & $\mathrm{U}^{236}$ & $\mathrm{U}^{235}$ & $\mathrm{U}^{234}$ \\
\hline Mean ratio & 0.998252 & 0.000000 & 0.007296 & 0.0000 \\
\hline Std. deviation & 0.0048696 & 0.0000066 & 0.00000256 & 0.0000 \\
\hline Atomic $\%$ & 99.2687 & 0.0000 & 0.7255 & 0.0000 \\
\hline Mean wt. & 236.2595 & 0.0000 & 1.7049 & 0.0000 \\
\hline wt.\% & 99.2779 & 0.0000 & 0.7164 & 0.0000 \\
\hline Mean atomic wt. & 237.9779 & & & \\
\hline
\end{tabular}


Table 5. Determination of isotopic ratio of uranium at different concentration ( $\mu \mathrm{g}$ /filament) at natural uranium solutions.

\begin{tabular}{lllll}
\hline Ratio, $\boldsymbol{\mu g}$ /filament & $\mathbf{U - 2 3 8}$ & $\mathbf{U}-\mathbf{2 3 6}$ & $\mathbf{U - 2 3 5}$ & $\mathbf{U - 2 3 4}$ \\
\hline 20 & 0.997532 & 0.000001 & 0.007314 & 0.0000054 \\
15 & 1.000783 & 0.000000 & 0.007316 & 0.000061 \\
10 & 0.998252 & 0.000000 & 0.007296 & 0.000085 \\
8 & 1.004333 & 0.000004 & 0.007300 & 0.000052 \\
6 & 1.001872 & 0.000003 & 0.007291 & 0.000056 \\
4 & 1.008944 & 0.000000 & 0.007300 & 0.000055 \\
2 & 1.003127 & 0.00000 & 0.007283 & 0.000054 \\
\hline
\end{tabular}

Table 6. Determination of isotopic ratio of uranium at different concentration enrichments.

\begin{tabular}{|c|c|c|c|c|}
\hline & \multicolumn{4}{|c|}{ Sample No. $110 \%$ enrichment., Conc.: 2000 ppm ; No. of Runs = 10, Vol.: $5 \mu 1=10 \mu \mathrm{g}$ / filament } \\
\hline Isotope & $\mathrm{U}^{238}$ & $\mathrm{U}^{236}$ & $\mathrm{U}^{235}$ & $\mathrm{U}^{234}$ \\
\hline Mean ratio & 1.000000 & 0.000688 & 0.110323 & 0.000795 \\
\hline Std. deviation & 0.0000 & 0.0000019 & 0.000053 & 0.0000026 \\
\hline Atomic\% & 89.9438 & 0.0618 & 9.9228 & 0.0715 \\
\hline Mean wt. & 241.0662 & 0.1459 & 23.3186 & 0.1673 \\
\hline wt.\% & 90.0580 & 0.0613 & 9.8101 & 0.00703 \\
\hline \multirow[t]{2}{*}{ Mean atomic wt. } & \multicolumn{4}{|c|}{237.7980} \\
\hline & \multicolumn{4}{|c|}{ Sample No.2 $0.32 \%$ enrichment. Conc. : 2000 ppm; No. of Runs $=10$, Vol.: $5 \mu 1=10 \mu \mathrm{g} /$ filament } \\
\hline Isotope & $\mathrm{U}^{238}$ & $\mathrm{U}^{236}$ & $\mathrm{U}^{235}$ & $\mathrm{U}^{234}$ \\
\hline Mean ratio & 1.000000 & 0.00168 & 0.003496 & 0.0000206 \\
\hline Std. deviation & 0.0000 & 0.0000054 & 0.0000071 & 0.0000045 \\
\hline Atomic $\%$ & 99.6328 & 0.0167 & 0.3483 & 0.0020 \\
\hline Mean wt. & 237.1260 & 0.0394 & 0.8185 & 0.0048 \\
\hline wt.\% & 99.6374 & 0.0165 & 0.3439 & 0.0020 \\
\hline \multirow[t]{2}{*}{ Mean atomic wt. } & \multicolumn{4}{|c|}{237.9887} \\
\hline & Sample No.3 & \multicolumn{3}{|c|}{$0.72 \%$ enrichment. Conc. : 2000 ppm; No. of Runs $=5$, Vol.: $5 \mu 1=1 \mu \mathrm{g} /$ filament } \\
\hline Isotope & $\mathrm{U}^{238}$ & $\mathrm{U}^{236}$ & $\mathrm{U}^{235}$ & $\mathrm{U}^{234}$ \\
\hline Mean ratio & 0.998252 & 0.0000 & 0.007296 & 0.000085 \\
\hline Std. deviation & 0.004870 & 0.0000 & 0.000003 & 0.000066 \\
\hline Atomic $\%$ & 99.2687 & 0.0000 & 0.7255 & 0.0058 \\
\hline Mean wt. & 236.2595 & 0.0000 & 0.7049 & 0.0135 \\
\hline wt.\% & 99.2779 & 0.0000 & 0.7164 & 0.0056 \\
\hline \multirow[t]{2}{*}{ Mean Atomic wt. } & \multicolumn{4}{|c|}{237.9779} \\
\hline & \multicolumn{4}{|c|}{ Sample No.4. Conc. : 1600 ppm; No. of Runs $=5$, Vol.: $5 \mu 1=15 \mu \mathrm{g}$ / filament } \\
\hline Isotope & $\mathrm{U}^{238}$ & $\mathrm{U}^{236}$ & $\mathrm{U}^{235}$ & $\mathrm{U}^{234}$ \\
\hline Mean ratio & 1.004333 & 0.000004 & 0.007300 & 0.000052 \\
\hline Std. deviation & 0.0034038 & 0.0000015 & 0.00000886 & 0.000004 \\
\hline Atomic\% & 99.2729 & 0.0003 & 0.7215 & 0.0051 \\
\hline Mean wt. & 236.2695 & 0.0070 & 1.6955 & 0.0019 \\
\hline wt.\% & 99.2822 & 0.0002 & 0.7124 & 0.0050 \\
\hline Mean atomic wt. & \multicolumn{4}{|c|}{237.9776} \\
\hline & \multicolumn{4}{|c|}{ Sample No.5. Conc. : $1200 \mathrm{ppm}$; No. of Runs $=5$, Vol. $: 5 \mu 1=20 \mu \mathrm{g}$ / filament } \\
\hline Isotope & $\mathrm{U}^{238}$ & $\mathrm{U}^{236}$ & $\mathrm{U}^{235}$ & $\mathrm{U}^{234}$ \\
\hline Mean ratio & 1.001872 & 0.000003 & 0.007291 & 0.000056 \\
\hline Std. deviation & 0.0054849 & 0.00000292 & 0.00000109 & 0.0000023 \\
\hline Atomic $\%$ & 99.2717 & 0.0002 & 0.7224 & 0.0055 \\
\hline Mean wt. & 236.2666 & 0.0004 & 1.6976 & 0.0129 \\
\hline wt.\% & 99.2811 & 0.0004 & 0.7133 & 0.0054 \\
\hline Mean atomic wt. & \multicolumn{4}{|c|}{237.9775} \\
\hline & \multicolumn{4}{|c|}{ Sample No.6. Conc. : 800 ppm; No. of Runs $=5$, Vol.: $5 \mu 1=15 \mu \mathrm{g}$ / filament } \\
\hline Isotope & $\mathrm{U}^{238}$ & $\mathrm{U}^{236}$ & $\mathrm{U}^{235}$ & $\mathrm{U}^{234}$ \\
\hline Mean ratio & 1.008944 & 0.000000 & 0.0073 & 0.0000 \\
\hline Std. deviation & 0.0046957 & 0.0000054 & 0.0000046 & 0.0000 \\
\hline Atomic\% & 99.2711 & 0.0000 & 0.7233 & 0.0000 \\
\hline Mean wt. & 236.2647 & 0.0000 & 1.6998 & 0.0000 \\
\hline wt.\% & 99.2804 & 0.0000 & 0.7143 & 0.0000 \\
\hline Mean atomic wt. & \multicolumn{4}{|c|}{237.9781} \\
\hline & \multicolumn{4}{|c|}{ Sample No.7., Conc.: 400 ppm; No. of Runs = 5, Vol.: $5 \mu 1=15 \mu \mathrm{g}$ / filament } \\
\hline Isotope & $\mathrm{U}^{238}$ & $\mathrm{U}^{236}$ & $\mathrm{U}^{235}$ & $\mathrm{U}^{234}$ \\
\hline Mean ratio & 1.003127 & 0.000000 & 0.007283 & 0.000054 \\
\hline Std. deviation & 0.0037031 & 0.00000262 & 0.00000697 & 0.000001 \\
\hline Atomic $\%$ & 99.2739 & 0.0000 & 0.7208 & 0.0053 \\
\hline Mean wt. & 236.2718 & 0.0000 & 1.6939 & 0.0124 \\
\hline wt.\% & 99.2830 & 0.0000 & 0.7118 & 0.0052 \\
\hline Mean atomic wt. & & 237.9781 & & \\
\hline
\end{tabular}



of Uranium and Boron by Thermal Ionization Mass Spectrometric Isotopic Dilution Technique

Table 7. uranium concentration measurements by isotope dilution technique.

\begin{tabular}{llllll}
\hline$\left[\mathbf{U}^{\mathbf{2 3 8}}\right]$ spike wt., g & {$\left[\mathbf{U}^{\mathbf{2 3 3}}\right]$ sample wt., g } & Mixing ratio & Mean ratio $\mathbf{U}^{\mathbf{2 3 3}} / \mathbf{U}^{\mathbf{2 3 8}}$ & $\mathbf{U}^{\mathbf{2 3 3}}$ found (ppm) & R.E [\%] \\
\hline 1.029 & 0.2453 & $12: 1$ & 0.0803 & 943 & 975 \\
0.2520 & 0.2440 & $3: 1$ & 0.3740 & 6.5 \\
\hline$\left[\mathrm{U}^{238}\right]=2422 \mathrm{ppm}$ & {$\left[\mathrm{U}^{233}\right]=1000$ ppm taken as unknown. $\quad \mathrm{R}=\mathrm{U}^{233} / \mathrm{U}^{238} \quad \mathrm{Ri}=0.000154$} & $\mathrm{Rp}=1483$
\end{tabular}

$\left[\mathrm{U}^{238}\right]=2422 \mathrm{ppm} \quad\left[\mathrm{U}^{233}\right]=1000$ ppm taken as unknown. $\quad \mathrm{R}=\mathrm{U}^{233} / \mathrm{U}^{238} \quad \mathrm{Ri}=0.000154 \quad \mathrm{Rp}=1483$

\section{Conclusions}

On the basis of the above findings, the isotopic dilution analysis for the determination of uranium and boron concentrations could be carried out with reasonable and reliable accuracy and reproducibility. The accuracy of the method depends on the purity of the isotopic material added (spike) as well as on the accuracy of the isotope analysis. The total weight of material containing the enriched isotope which is added is generally known with great accuracy.

\section{References}

[1] Y. J. Park, H. Y. Pyo, K. Song, B. C. Song, K. Y. Jee and W. H. Kim, Bull. Korean Chem. Soc., 27 (10) (2006) 16091612 .

[2] T. U. Probost, Fresenius Z. Anal. Chem. 364 (1999) 391.

[3] P. W. May, K. N. Fox, N. A. Younes, C. M. Beardmore, Diamond and Related Materials 6 (1997) 450.

[4] C. J. Park, Bull. Korean Chem. Soc. 23 (2002) 1541-1544.

[5] A. Lamberty, V. Holland, A. Verbruggen, F. Hendrickx and P. Debievre, Fresenius Z. Anal. Chem. 332 (1988) 645-647.

[6] R. M. Rao, A. R. Parab, K. S. Bhushan and S. K. Aggarwal, Microchim Acta 169 (2010) 227-231.

[7] G. Menard, I. Vlastelic, D. A. Ionov, E. F. Rose-Koga, J. Piro and C. Pin, Chemical Geology 354 (2013) 139-149.

[8] W. Arden and N. H. Gale, Anal. chem. 46 (1974) 687-691.
[9] M. Haldimann, M. Baduraux, A. Eastgate, P. Froidevaux, S O'Donova, D. Von Gunten and O. Zoller, J. Anal. At. Spectrom 16 (2001) 1364-1369.

[10] A. G. Adriaens, J. D. Fassett, W. R. Kelly, D. S. Simons and F. C. Adams, Anal. Chem. 64 (1992) 2945-2950.

[11] D. Vopalka and J. Cabical, Int. J. Mass Spec. and Ion Physics 48 (1983) 401-404.

[12] V. J. Heinonen and R. J. Korhonen, J. Radioal. Chem. 64, No. 1-2 (1981) 65-72.

[13] L. Koch, Radio Chim. Acta. 12 (1969) 16.

[14] J. Krtil, F. Sus and J. Mensl, J. Radioanal. Chem. 28 (1975) 109-118.

[15] F. Sus and J. Krtil, J. Radioanal. Chem. 15 (1979) 143-151.

[16] E. J. Spitzer and J. R. Sites, "Isotopic mass spectrometry of the elements" USAEC, Rept., ORNL-3528.

[17] M. W. Lerner "The Analysis of Elemental Boron", TID25910 (1970).

[18] R. O. Inlow and J. M. scarborough, Anal. Chem. 48 (1976) 1357.

[19] A. Henrion, Fres. J. Anal.Chem. 350 (1994) 657-658.

[20] J.Tolgyessy, T. Braun and M. Kyrs,"Isotope Dilution Analysis" pergamon press, Oxford (1972)

[21] W. Beyrich and E. Drosselmyer, "The Interlaboratory Experiment" IDA-72 on M.S.I.D.A.," kfk-1905/1 and Kfk1905/11 (July 1975).

[22] H. O. Finely and E. E. Luang, USAEC Rept., NBL-170 (1961) "Mass Spectrometric Determination of Boron Isotopic Abundance in the Near Normal Range 